\title{
Mother tongues, governmentality, and protectionism ${ }^{1}$
}

\author{
ALASTAIR PENNYCOOK
}

\section{Abstract}

This paper questions the essentialist status of the mother tongue as the cornerstone of language policy. One reason for doing so is the need for a constantly skeptical questioning that must be at the heart of any critical project. More specifically, it is important to raise questions about what we mean by "language" and what different concepts, ideologies, or discourses we mobilize by particular constructions of the term. The substance of the argument in this paper, however, is related to ways in which the mother tongue was frequently promoted as a strategy of colonial language policy. Viewed through the concepts of governmentality and protectionism, it can be argued that the mother tongue has as much to do with continuity in the construction of the Other as with community or individual rights. These ideas will be elaborated through a brief consideration of British language policy in Malaya and Hong Kong. I conclude by arguing for the importance of considering alternative language strategies, such as disinvention.

\section{Introduction}

Whether from the point of view of linguists' butterfly-collecting approach to language preservation, liberal concerns with the maintenance of diversity, or arguments in favor of individual and community rights, the mother tongue, rather like the Virgin Mary, remains something in whose direction the congregation of language educators should always genuflect. Indeed, the notions of the mother tongue and mother-tongue education are often held up as political icons like democracy, universal education, or gender equality. And, it must be said, to the extent that an emphasis on mother-tongue rights in education and elsewhere constitutes a highly significant position against the conservative and racist attacks on bilingual education, multilingual community language use, or ethnic identity, 


\section{A. Pennycook}

it remains one of the most significant domains of political action within applied and educational linguistics.

To question the mother tongue therefore renders one politically suspect from any broad liberal-leftist alliance. As some angry responses (alongside numerous very positive comments) to the original presentation of these papers on a conference panel suggested, to engage in this type of questioning was tantamount to aligning ourselves with the political right by reproducing arguments that had been used to promote English (or other major languages) at the expense of minority languages; we were guilty of ignoring the contexts of language use, blindly following the particular and suspect agendas of those we quoted, or engaging in nothing but "postmodern language games." These are troubling accusations to which I shall return. And they suggest that "questioning the mother tongue" may well be akin to daubing paint on the Virgin Mary. In some ways, it is the very untouchability of the mother tongue that motivates my desire to question it. But there are also other concerns that are not reducible to iconoclasm, conservativism, or postmodernism for its own sake.

The first set of issues has to do with the need constantly to question the tools we use for our work. In general, this is part of what I see as the constantly skeptical questioning that must be at the heart of any critical project. Others view this as politically disabling, suggesting that the only way forward for critical work is to go into battle with assurity, with concepts such as language rights, linguistic imperialism, hegemony, and ideology tightly sewn up and ready for use. I'm more skeptical. It seems to me that any broad critical project in language education requires not only a form of politics that brings questions of access, power, disparity, desire, difference, and resistance to the fore, but also an intellectual skepticism that is always prepared to question the status and meaning of concepts in the field (see Pennycook 2001). More specifically, I think we always need to ask hard questions about what we mean by "language" and what different concepts, ideologies, or discourses we mobilize by particular constructions of the term.

The second set of issues has to do with my attempt to understand various contexts of colonial language policy. What emerges in this work is the frequent use of mother-tongue education as part of colonial strategies of governance. I shall argue below that if we view colonial language policy in terms of governmentality, that is to say as "an array of technologies of government" (Rose 1996: 42) rather than in terms of state-based or national policy, a rather more complex picture of the role of mothertongue promotion emerges. This argument sheds light on the continuity of what I term protectionism, or the ways in which mother-tongue language 
policy has been intertwined with particular ways of constructing the Other. I shall return to these issues in much greater depth below. First, I shall turn to the notion of languages as constructs.

\section{Languages as social and political constructs}

Of course, on one level, questions about the ontological status of languages is nothing new. While on the face of things we may be fairly content to assume the existence of languages because we all speak something and it differs to various degrees from the way others speak, on another level the problems with defining linguistically what one is, or where its boundaries are, remain. One position on this is to argue that although languages are predominantly political rather than linguistic categories and that the boundaries between languages are fuzzy, we can nevertheless say with some assurity that there are some 6,500 languages around the world, many of which are endangered. Thus many linguists (e.g. Dixon 1997) would argue that we can simply separate the political from the linguistic definitions of language along the lines, more or less, of a subjective (political)/objective (linguistic) divide. From this point of view, languages exist independent of their description, and while some arguments may continue over defining where one language ends and the next begins, it is broadly possible to describe and enumerate languages.

Other linguists are less sanguine, however. Discussing language use in Papua New Guinea, Romaine (1994) asks how we can come to terms with the problem that speakers may claim to speak a different language when linguistically it may appear identical. In his discussion of "nativity of language" Annamalai (1998) draws on Benedict Anderson's (1991) notion of "imagined communities" to highlight the ways in which communities of speakers are cultural and political constructs. Since the Tamil community, in one imagining, includes Tamils in Tamilnadu, South Africa, and Mauritius, many of whom in the latter two contexts may have minimal proficiency in this "mother tongue," it is evident that the linguistic nativity of a community is a cultural and political, rather than a linguistic, construct. Studies of multilingual communities in India, Africa, and Papua New Guinea suggest that it is quite possible to have multiple mother tongues. Makoni (1999: 143) suggests that in the South African context, "analytic linguistic categories such as multilingualism, language as code switching, and medium of instruction ... prevent nuanced appreciation of the full complexity of African sociolinguistic contexts." 


\section{A. Pennycook}

As Romaine points out, "the very concept of discrete languages is probably a European cultural artefact fostered by processes such as literacy and standardization. Any attempt to count distinct languages will be an artefact of classificatory procedures rather than a reflection of communicative practices" (1994: 12). Mühlhäusler (1996: 35) lends support to this view when he suggests that "The difficulties of distinguishing between languages, dialects, communalects and such phenomena encountered by present-day linguists ... do not so much reflect their inability to find these 'objects' as their non-existence." From this point of view, then, the notion that languages exist as objective entities is highly questionable. Furthermore, Mühlhäusler and Romaine are suggesting that what are reflected in linguistic descriptions are not so much languages themselves (indeed, they are produced by such descriptions) but rather particular European beliefs about languages. Makoni (1999: 144) concurs, arguing that by recognizing eleven official languages, the South African Constitution "divides speech forms into eleven separate and mutually exclusive boxes, creating a self-serving amnesia, which encourages South Africans to unremember ... the historical and material conditions in which the so-called languages were created and manufactured."

The linguistic project to describe and maintain languages, therefore, is often pursued with an epistemological naivety that on the one hand fails to grasp that the process is as much about production as it is about description, and on the other hand insists on the existence and the necessary primacy of a mother tongue. Nakata (2000: 116) chides linguists in the Torres Straits Islands for only "being interested in the project of recording and preserving traditional languages" and not being "attuned to the current political and economic concerns of Islanders, nor guided by a wider view of the relationship between languages, literacy education, and educational outcomes." A major concern here, then, is that the view that there are minority, mother-tongue languages threatened by other, dominant languages may be a product of the very context from which dominant European languages emerged. This is the argument that Rajagopalan (1999: 201) makes in his critique of the notion of (English) linguistic imperialism: "the very charges being pressed against the hegemony of the English language and its putative imperialist pretensions themselves bear the imprint of a way of thinking about language molded in an intellectual climate of excessive nationalist fervour and organized marauding of the wealth of alien nations - an intellectual climate where identities were invariably thought of in all-or-nothing terms". Thus Rajagopalan is suggesting that the critical discourses employed by notions such as linguistic imperialism draw on the same modernist European frameworks that have been the cause of precisely what they seek to critique. 
The very notion of language frequently used to discuss mother tongues, language maintenance, linguistic imperialism, and language education, therefore, may in many cases be a colonial European construct. This is not to deny that many people have a name for what they speak that distinguishes it from what is spoken by other communities. Rather the point is, first, that many "languages" are colonial or missionary inventions: "The notion of invention," suggests Makoni (personal e-mail communication, 1999), "foregrounds the historicity of the social conditions in which African vernaculars were created and by extension draws attention to the manner in which they were (un)systematically constructed. In other words, missionaries were not sinfree in their creation of African vernaculars." Similarly, many linguists today are far from sinfree in their creation of languages around the world. And second, not only may the things themselves be inventions, but the many attendant assumptions about identity and language use may to a large extent be a product of a particular cultural and historical period. And constantly to replay such concepts may reproduce rather than oppose colonial discourse. As Coulmas (1998: 71-72) suggests, then, "the nineteenth-century romantic idea that pegs human dignity as well as individual and collective identity to individual languages is contingent. ... In particular, the perception that language shift is a catastrophe cannot be expected to withstand the current of ideological fashion." It is to the historical continuity of some of these constructs that I now wish to turn.

\section{Historical contexts and governmentality}

The principal argument that I wish to focus on here derives from the historical use of language policy as an arm of colonial governance. I have written about this extensively elsewhere (Pennycook 1998, 2000), so I shall briefly summarize the most important issues here. There are two main points that I wish to make. First, colonial language policies frequently promoted education in mother tongues and did so for very clear political reasons. The apartheid system in South Africa, for example, "used promotion of the mother tongue principle, specifically the advancement of the indigenous African languages as subject and medium of instruction, as a central instrument of the policy of divide and rule" (Barkhuizen and Gough 1996: 453-454). But, second, this process should not be seen only in terms of basic political strategies such as "divide and rule"; rather, it is important to view education in mother tongues as linked to far more complex modes of governmentality and to forms of protectionist discursive production. 


\section{A. Pennycook}

By this I mean, on the one hand, that the choice of medium of education was frequently linked to an array of cultural, moral, and educational strategies of government that were realized through school curricula. This notion of governmentality, then, helps shift an understanding of governance away from a focus on the intentional and centralized strategies of government authorities, to focus instead on the multiplicity of ways in which practices of governance may be realized. In so doing, it moves us away from a focus on the State as an intentional actor that seeks to impose its will on the People and instead draws our attention to much more localized and often contradictory operations of power. It also suggests that in order to understand how the regulation of domains of life may be effected, we need to look not so much at laws, regulations, policing, or dominant ideologies as at the operation of discourses, educational practices, and language use. On the other hand, the emphasis on mother-tongue education was interlinked with forms of Orientalism that were aimed at the preservation of cultures as viewed through the exoticizing gaze of the colonial administrator. Viewed in terms of protectionism this attempt to construct and preserve people and their languages clearly connects to more current forms of linguistic and cultural preservation.

An early assumption of mine was that a cornerstone of colonial rule was the promotion and enforcement of colonial languages. Yet, while the broader economic dictates of empire and the imperializing ideologies of Anglicism (pro-English policies) clearly played important roles within the empire, language policies were also tied both to Orientalist views on the need to preserve colonized cultures in a pristine state of precolonial innocence, and to local conditions of control. As Smith (1987: vii) explains in the context of education in Papua New Guinea, "Within the colonial context the type of education provided for subject peoples can be seen more as serving the requirements of those who provided it rather than those for whom it was provided." Education, therefore, "was a means of political, economic and social control in the colonial state." Education was seen as a crucial means for more effective governance of the people, and language policy was related to finding effective means of providing such education.

The solution to the need for education to produce a new generation of colonial subjects, more able to participate in colonial capital as both producers and consumers, more willing to accept the conditions of foreign occupation, was to be found not so much through the provision of an education in English, but rather through the far more widespread provision of education in vernacular languages. The development of language policies in Malaya can be seen to have followed a tendency to 
"play safe" and promote local languages rather than English. Colonial administrators repeatedly warned against the dangers of an education in English, fearing it would create "a discontented class who might become a source of anxiety to the community" (E.C. Hill in the 1884 Report on Education in the Straits Settlements; Straits Settlements 1884: 171). This commonly held position is echoed by Frank Swettenham's argument in the Perak Government Gazette (6 July, 1894): "I am not in favour of extending the number of 'English' schools except where there is some palpable desire that English should be taught. Whilst we teach children to read and write and count in their own languages, or in Malay ... we are safe" [emphasis in original]. Thus, as Loh Fook Seng (1970: 114) comments, "Modern English education for the Malay then is ruled out right from the beginning as an unsafe thing."

While ruling out English as an unsafe thing, these administrators on the other hand saw great value in the promotion of vernacular education. In an article on vernacular education in the State of Perak, the Inspector of Schools, H.B. Collinge, explained the benefits of education in Malay as taking "thousands of our boys ... away from idleness," helping them at the same time to "acquire habits of industry, obedience, punctuality, order, neatness, cleanliness and general good behaviour." Thus, after a boy had attended school for a year or so, he was "found to be less lazy at home, less given to evil habits and mischievous adventure, more respectful and dutiful, much more willing to help his parents, and with sense enough not to entertain any ambition beyond following the humble home occupations he has been taught to respect." And not only does the school inculcate such habits of dutiful labor but it also helps colonial rule more generally since "if there is any lingering feeling of dislike of the 'white man', the school tends greatly to remove it, for the people see that the Government has really their welfare at heart in providing them with this education, free, without compulsion, and with the greatest consideration for their mohammedan sympathies" (cited in Straits Settlements 1894: 177).

Meanwhile in Hong Kong, E.J. Eitel, Inspector of Schools in Hong Kong from 1879 to 1897 , a former German missionary, and a "sound orientalist and sinologist" (Lethbridge 1983 [1895]: vii), who had written a dictionary of Cantonese and books on Buddhism and fengshui, was most concerned that education should give students sufficient grounding in morality. Indeed, although he clearly supported the teaching of English, he also argued that students in the village schools were getting a better education than those receiving a secular education in English. By studying Chinese classics, students learn "a system of morality, not merely a doctrine, but a living system of ethics." Thus they learn "filial 


\section{A. Pennycook}

piety, respect for the aged, respect for authority, respect for the moral law." In the government schools, by contrast, where English books are taught from which religious education is excluded, "no morality is implanted in the boys" (Report 1883: 70). The teaching of Chinese, Eitel argued, is "of higher advantage to the Government" and "boys strongly imbued with European civilization whilst cut away from the restraining influence of Confucian ethics lose the benefits of education, and the practical experience of Hongkong is that those who are thoroughly imbued with the foreign spirit, are bad in morals."

What also becomes increasingly clear in Hong Kong is the way in which educational policy reacted to local conditions of unrest. The 1911 revolution in China, for example, and the increased sense of nationalism among the Chinese was to have profound effects on Hong Kong's schools. Thus, at the same time that the government was promoting vernacular education for its conservative ideals, there was also the concern that this same vernacular education was feeding into pro-Chinese and anticolonial national sentiment. As Chan (1994: 32) points out, "To counter the Chinese revolution's undermining impact on the conservative ideas and traditional values taught by Hong Kong's several hundred vernacular schools, which to that point had remained unassisted and uncontrolled by the government, Governor May enacted in August 1913 the Education Ordinance, which required every school to register with the director of education, conform to government regulations, and submit to official inspection." This educational ordinance, which, according to Sweeting (1992: 45) represents "the high-water mark of colonial power and authority over education," signalled the move not merely to support but also to regulate vernacular education.

Following the massive 1925 strike and boycott of goods in Hong Kong, R.H. Kotewall (CO 129/489: 455) ${ }^{2}$ pointed directly to the schools as the source of problems and recommended increased supervision: "Obviously the first remedy is an increased watchfulness in the schools. Special care should be exercised in the supervision of the vernacular schools in particular, for these can the more easily become breeding grounds for sedition." His recommendations go beyond this, however, for he then goes on to recommend particular orientations for Chinese school curricula: "The Chinese education in Hong Kong does not seem to be all that it should be. The teaching of Confucian ethics is more and more neglected, while too much attention is being paid to the materialistic side of life. ... In such a system great stress should be laid on the ethics of Confucianism which is, in China, probably the best antidote to the pernicious doctrines of Bolshevism, and is certainly the most powerful conservative course, and the greatest influence for good." Thus, "money 
spent on the development of the conservative ideas of the Chinese race in the minds of the young will be money well spent, and also constitutes social insurance of the best kind" (CO 129/489: 455-456). These, then, were the crucial tools of governmentality through language in education policies. But, as these examples also reveal, the particular conjunction of language, education, and culture promoted by these various colonial administrators was part of a very singular construction of the cultures that interested them.

While one aspect of this vernacular education was to promote loyalty, obedience, and acceptance of colonial rule, another dimension was tied to the Orientalist interests of many of the scholar-administrators who were closely connected to educational policies. In Malaya, Swettenham - who as we saw above, warned against the teaching of English in Malaya "earned his Knighthood on the strength of his ability to understand the ignorant unspoilt Malays," while another orientalist administrator, Wilkinson, "believed as many an Englishman has believed before him and since that the native must not be taken away, must not be uprooted from his fascinating environment, fascinating to a brilliant Malay scholar" (Loh Fook Seng 1970: 114). Thus, as Loh Fook Seng goes on to suggest, "Much of the primitive Malay education that continued to be supplied by the British Government was in no small degree due to this attempt to preserve the Malay as a Malay, a son of the soil in the most literal sense possible." Here, then, we can start to see how language policies favoring education in vernacular languages or mother tongues was bound up with the construction and preservation of colonial images of the colonized.

In Hong Kong, Kotewall's arguments for a more conservative education through Chinese to counter Chinese nationalism were supported most actively by the Governor, Sir Cecil Clementi, a long-term colonial administrator in Hong Kong, and a scholar of Chinese folk songs. Inviting senior Chinese literati to Government House in 1927, Clementi addressed them in Cantonese and asked them to help him to develop a curriculum that would emphasize traditional morality and scholarship, a curriculum based on orthodox Confucianism emphasizing social hierarchy and subservience to patriarchal authority (Luk 1991). Clementi's goal, then, was to counter the rising tide of Chinese nationalism by emphasizing traditional Chinese notions of hierarchy and loyalty. Thus, "appeal was made to the cultural tradition of the native people to help safeguard foreign rule against the growth of nationalistic feelings among the younger generation" (Luk 1991: 660). Often far more important, therefore, than the civilizing zeal of English teaching was the conservative use of vernacular education, developed and implemented by colonial administrators and Orientalist scholars. 


\section{A. Pennycook}

Singh (1996) describes the apparent paradox that lay at the heart of this colonial study and preservation of other languages and cultures in India: "on the one hand, the Orientalists as civil servants shared the standard colonial belief in the superiority of Western knowledge and institutions. On the other hand, these lndologists 're-discovered' a glorious India by identifying a certain resemblance between East and West in a shared ancient past" (Singh 1996: 71). It was from amid these paradoxical studies of Indian, Malay and Chinese culture that conservative policies for the preservation of culture and knowledge - as defined by these colonial scholars - emerged, and, most importantly, policies to promote conservative forms of education were developed. Language in education policies in British colonies were thus oriented toward the preservation of Orientalist understandings of local cultures and the promotion of vernacular education as a means of social regulation.

\section{Mother tongues and protectionism}

It is of course immediately important to note that these observations about the promotion of education in local (vernacular) languages as an aspect of colonial governance by no means constitute an argument against the use or promotion of mother tongues in current language policies. ${ }^{3}$ Rather it suggests, first, that we need to understand the complexity of the contexts in which one language or another is being supported. That both English and vernacular languages could be promoted as aspects of colonial governance by different colonial administrators at different times suggests that we cannot consider the support of one language or another as inherently preferable. It depends what they were being used for. Second, language in education was part of the processes of governmentality and protectionism; the support for education in vernacular languages was part of the production of otherness, the creation of static traditionalism. Colonialism offered a series of dichotomous relations, which have set the agenda for many colonized and colonizing societies since that time.

It has been common to divide colonies into two broad types: those such as India, Malaya, Hong Kong, and many others where Europeans were a small minority, and those so-called "settler colonies" such as Canada, Australia, and New Zealand where, as one writer put it, "British settlers ... were true colonists who went to make new homes in empty lands .... They settled down to farm their new lands in peace, as no man's rival [sic]" (Eyre 1971: 150). In conjunction with this division it has 
often been assumed that language and cultural policy followed a divideand-rule strategy for the former category and an assimilatory strategy for the second. But, just as the discussion above shows that vernacular education cannot be reduced to an easy equation with dividing and ruling, so any strategy oriented potentially toward some form of so-called assimilation has to be seen in much more complexity. The different ways of dealing with those constructed as "other" within a colonial society were multiple. And there were also many elements of commonality across the different types of colonies, particularly in the strategy of protectionism.

This was perhaps nowhere more evident than in the workings of the Australian Aboriginal Protection Society, which first met in Melbourne in 1838 and was aimed at providing welfare and protection for Aboriginal people. It was eventually superseded and taken over by the New South Wales government in 1883 as the Aboriginal Protection Board. As George Thornton, the first government-appointed "Protector of Aborigines," wrote in his first report to the Governor in 1882, prior to the setting up of the Board, "Government aid should be limited as far as it possibly can be to the true Aborigines only. Whilst I wish to see the half-castes civilized, educated, and cared for, yet they should not be permitted to grow into a pauper or quasi gipsy class, but taught to be able and compelled to work for their own living, and thereby ultimately merge into the general population" (cited in Fletcher 1989b: 65). Thus, at its very inception, the Board started the dual process of "protection" for "true Aborigines" and assimilation for "half-castes," "quadroons," "octoroons," etc. And at the same time it was central in this process of defining aboriginality according to contemporary views on "race" and "blood" (see Fletcher 1989a, 1989b; Young 1995). Protection thus had two crucial aspects: it started the process of developing segregated reserves for those defined as "true Aborigines," and at the same time it started the process of removing children defined as "half-caste," etc., from their mothers. The influential report in 1882 on Maloga and Warangesda Aboriginal mission stations suggested that "the half-caste mothers" of half-caste and quadroon children would "willingly part with them, if assured that it would be for their benefit" (cited in Fletcher 1989b: 67). Protectionism here, then, becomes a crucial strategy of definition, segregation, and separation.

Commenting on Edward Said's remark that "the worst and most paradoxical gift" of colonialism was "to allow people to believe that they were only, mainly, exclusively, white, or black, or Western, or Oriental" (1993: 336), Suresh Canagarajah (1999: 182) points out that "To stick stubbornly to one's indigenous discourses or to surrender unconditionally to English are positions of accommodation to the imperialist dynamics that offer post-colonial subjects only negative or stereotypical identities 


\section{A. Pennycook}

or absorb then into [the] center's cultural logic." The dichotomization between pure/traditional and impure/modern/hybrid can be seen as a central and continuing trope of Aboriginalism (Hodge and Mishra 1990). According to Walton (1996: 87), "Aboriginalism divides indigenous people into two groups, the 'traditional' and the 'non-traditional', attributing authenticity and homogeneity to the first group while describing the other group as having lost their culture." It is in part against such a background that we need to understand Nakata's (2000: 112) arguments against programs designed to promote literacy in Torres Strait languages or Creole: "Why do we need to read and write in our first language which is after all still a robust oral tradition?" Nakata (2000: 113) argues against essentialist views of culture and instead suggests that change may be as important as preservation, since "it is not just the 'essence' of our culture that is so intrinsic to us but it is also our capacity to form and reform it as the contexts of our lives change."

In the context of South African language policy, Makoni argues that "Emerging discourses about multilingualism derive their strength and vitality through a deliberate refusal to recollect that in the past multilingualism has always been used to facilitate exploitation of Africans ... . Proponents of multilingualism thus become ideological captives of the system they are seeking to challenge" (Makoni 1998a: 244-245). "The battle for independence," suggests Makoni (1998b: 162-163), "is simply not won by opting for vernaculars over English as normally articulated in the decolonisation literature ... . From UNESCO to the multicultural lobby the potential negative effects of learning through vernaculars is not addressed as it is assumed that it is cognitively and emotionally advantageous that a child learns through such a medium, overlooking as it does the colonised images encoded in such versions of African vernaculars." While it might be tempting to suggest that such views apply only to the South African context and the legacies of apartheid and Bantu education policies, I would suggest that there is a far wider case to be made that it applies to many contexts throughout the world.

As Nakata (1999: 14) puts it, "the most damaging aspect of the principle of culture preservation and promotion ... is that it has not only become a panacea for all our ills but has also become so regulatory that it precludes Islanders such as myself and indigenous people all over this country from pursuing the issues that we want to pursue." While there are indeed very good arguments for mother-tongue or vernacular literacy, these are also frequently bound up with protectionist (preservationist) discourses that form part of the broader field of Orientalism and Aboriginalism. Protectionism becomes part of the 
process of the construction of the Other, even being part of a movement to define exactly who is in and who is out. It is important, then, to consider that whether or not we are promoting mother-tongue education, bilingualism, monolingualism, or multilingualism, we may be reproducing a colonial legacy of language constructs. To fight the battle in these terms is to reproduce, not oppose, colonialism. We tend to get stuck here between old polarities: Anglicism vs. Orientalism, mother tongues vs. global languages, preservation vs. assimilation, multilingualism vs. monolingualism. Some argue for English Only (a position that thinly conceals a host of other racist and anti-Other sentiments); others for the complementarity of international and traditional languages (a position that replicates many of the colonial constructs of the past centuries); others for language rights, multilingualism, and mother tongues (positions that may nevertheless reproduce the same notions of language that are part of the problem). Is there another strategy?

\section{Conclusion: disinventing languages}

All these examples point to the importance of avoiding overarching statements about the mother tongue. Rather, we need to work contextually. But there are two dimensions to this. On the one hand, this can be understood in terms of locating any discussion of mother-tongue education in specific linguistic, cultural, discursive, social, political, and economic contexts: we can only understand the specific configurations of what languages are used, what they represent, and what values they may carry by understanding the complexity of a specific context. Yet such a position may still allow for an essentialist notion of the mother tongue; this is not the abstract universalist notion of mother tongues as the same for everyone everywhere, but still a view that suggests that the notion of the mother tongue is shared across communities but related in different ways to different contexts. The arguments here, by contrast, not only locate discussions about the mother tongue in specific contexts but also relativize the concept. For many, while the first is necessary, the second is problematic since it does not allow for an abstract or objective concept of "the mother tongue" around which we can organize politically. From this point of view, while the politics of mother-tongue support need to be contextually understood, the mother tongue remains a universal category lurking behind such contexts. From my point of view, it is not only the effects of mother-tongue support that are locally contingent but also the meanings of mother tongues that are contextually produced. 


\section{A. Pennycook}

A related point has to do with the challenge that the arguments here are the same as those used to promote dominant languages or deny language rights. There is a crucial issue here: what do we mean by "the same"? One thing that emerges from the articles collected here is that on the one hand, very similar sounding arguments in favor of mother-tongue education have been made from radically different political orientations; and on the other, quite different arguments about mother-tongue education may be made to support quite similar political orientations. This is by no means a trivial point, for it suggests a certain political naivety if we try to read off political motivations from surface manifestations of "good" political projects - that is, if you support mother tongues, you're on the right side. At another level this points to a major unexplored question in critical discourse and policy analysis, namely that similar texts may be produced by different discourses, or that different texts may be products of similar discourses: that is, despite claims to the contrary in much critical discourse analysis, there is no simple isomorphism between text and ideology (discourse). Which means, in turn, that we cannot simply read statements as necessarily reflecting a particular

discourse. We need to understand the context and the discourse in greater depth. Thus, if arguments here appear to be "the same" as arguments in favor of the promotion of English, we need to ask how that can come to be, rather than assume that therefore they mean the same thing (and see Ricento 2000 for a related argument).

None of this is to deny that we live in a fundamentally inequitable world and that language plays a highly significant role in the reproduction of that inequality, as both object and medium of division. The argument that mother-tongue education may be used as part of social control does not mean we should reject the notion, but it raises concerns. How do any of the arguments here relate to Tove Skutnabb-Kangas's (2000) massive and significant recent book, Linguistic Genocide in Education or Worldwide Diversity and Human Rights?, the cornerstone of which is to argue for the need for linguistic rights (predominantly but not only mother-tongue rights) in the face of the global threat to linguistic diversity? The issues I have been raising in this article do not suggest that we should abandon the notion of the mother tongue, but rather that we should understand it as a strategically essentialist (cf. Spivak 1993) argument. As such, it is a politically important argument, but at the same time a dangerous one. The strategic use of essentialism whether we are claiming gendered, sexual, cultural, or linguistic identity - is useful for mobilization and legislation, but it may also reproduce those fixed categories of identity that many wish simultaneously to avoid. 
I have elsewhere (Pennycook 2001) argued that part of any critical applied linguistics is the "restive problematization of the given" (Dean 1994), the need not only to link applied linguistics to broader social and political questions but also constantly to question the received categories of linguistics and applied linguistics. Such a questioning must include even those most basic concepts such as language and mother tongue. This is not to engage in questioning merely for its own sake but to engage with the problem that all such terms are historical constructs and carry some of the weight of that historical baggage with them. Alongside the strategic use of essentialism, therefore - the mobilization of notions such as linguistic imperialism, linguistic genocide, language rights, mother tongues - there is also the need for strategic problematization. There are times to strategically essentialize, and times to strategically problematize. What I am trying to offer here, then, are some concerns to be read in parallel with the work of Skutnabb-Kangas and other tireless campaigners for language rights, an alternative strategy that seeks not so much to solidify but to dissolve, not so much to support mother-tongue education but to disinvent language.

Apart from arguing that we need to understand language policies contextually (where the notion of context is used to imply a broad range of physical and discursive complexity), another way forward, therefore, is to start to rethink the notion of language. Makoni's argument for the "disinvention of languages" presents one of the most provocative challenges here. For Makoni it is the very problem of the European construct of languages that is disenfranchising; even talk of multilingualism, he suggests, reproduces the same colonial constructs. According to Makoni (personal communication, 1999), "the promotion of African languages is a retrospective justification of a bygone era" and "a prioritisation of reified linguistic boxes over human concerns." The "celebrated African multilingualism is viewed through monolingual lenses." "Unless African languages are disinvented," he suggests, "some ways of conceptualization of the social world consistent with European missionary imperialism will be sustained into the next century."

This notion of disinvention is still in process of conceptualization. It is clearly a postcolonial strategy to counter the process of invention produced by colonialism. It is "a serious effort to capture current language practices which are generally pan-ethnic in use, although conceptualised by most linguists in ethnic terms" and "a serious effort to move away from the boxing metaphor typical of most ideas in applied linguistics." "Disinvention argues that African languages in their current ways of conceptualisation are European scripts." This, I think, is a fascinating and provocative challenge. How can we work toward the 


\section{A. Pennycook}

disinvention, rather than the reification, of languages? Such a question might lead us to address questions of language in education rather differently, not focusing so much on reified notions of dominant languages and mother tongues as on trying to understand the complex and hybrid mixtures of semiotic tools that are actually used.

University of Technology

Sydney

\section{Notes}

1. This paper was originally given as "Mother tongues, literacy and colonial governmentality" at the AAAL Conference in Vancouver, 2000. For the development of the ideas here I am indebted to the many discussions with members of the panel, Gerda de Klerk, Juliet Langman, Tom Ricento, Jim Tollefson, and Terry Wiley, my ongoing debates with Joe LoBianco, and my correspondences with Sinfree Makoni. Some of the materials here are also appearing in other recent papers (Pennycook 2000, 2002).

2. Colonial Office Documents.

3. It is also worth observing here that vernacular and mother-tongue education are by no means the same thing, the first being concerned primarily with a broad notion of local languages, the second looking more specifically at what is actually used by particular speakers. For the purposes of this paper I have not pursued in greater depth the mismatch between what was considered a vernacular language and what languages were actually used.

\section{References}

Anderson, Benedict (1991). Imagined Communities: Reflections on the Origin and Spread of Nationalism, 2nd ed. London: Verso.

Annamalai, E. (1998). Nativity of language. In The Native Speaker: Multilingual Perspectives, R. Singh (ed.). New Delhi: Sage.

Barkhuizen, Gary; and Gough, David (1996). Language curriculum development in South Africa. TESOL Quarterly 30(3), 453-472.

Canagarajah, Suresh (1999). Resisting Linguistic Imperialism in English Teaching. Oxford: Oxford University Press.

Chan Ming, K. (1994). Hong Kong in Sino-British conflict: mass mobilization and the crisis of legitimacy, 1912-1926. In Precarious Balance: Hong Kong between China and Britain, 1842-1992, M.K. Chan (ed.), 27-58. Hong Kong: Hong Kong University Press.

Colonial Office Records, Series 129. Colonial Office Documents.

Coulmas, Florian (1998). Language rights - interests of state, language groups and the individual. Language Sciences 20(1), 63-72.

Dean, Mitchell (1994). Critical and Effective Histories: Foucault's Methods and Historical Sociology. London: Routledge.

Dixon, R. (1997). The Rise and Fall of Languages. Cambridge: Cambridge University Press. 
Eyre, A.G. (1971). An Outline History of England. London: Longman.

Fletcher, J.J. (1989a). Clean, Clad and Courteous: A History of Aboriginal Education in New South Wales. Sydney: Southwood.

- (1989b). Documents in the History of Aboriginal Education in New South Wales. Sydney: Southwood.

Hodge, Robert; and Mishra, Vijay (1990). Dark Side of the Dream: Australian Literature and the Postcolonial Mind. Sydney: Allen and Unwin.

Lethbridge, H.J. (1983 [1895]). Introduction to Europe in China, E.J. Eitel. Hong Kong: Oxford University Press.

Loh Fook Seng (1970). The nineteenth century British approach to Malay education. Jurnal Pendidekan 1(1), 105-115

Luk Hung-Kay, B. (1991). Chinese culture in the Hong Kong curriculum: heritage and colonialism. Comparative Education Review 35(4), 650-668.

Makoni, Sinfree (1998a). African languages as European scripts: the shaping of communal memory. In Negotiating the Past: The Making of Memory in South Africa, S. Nuttall and C. Coetzee (eds.), 242-248. Oxford: Oxford University Press.

- (1998b). In the beginning was the missionaries' word: the European invention of an African language: the case of Shona in Zimbabwe. In Between Distinction and Extinction: The Harmonisation and Standardisation of African Languages, Kwesi Kwaa Prah (ed.), 157-164. Johannesburg: University of Witwatersand Press.

-(1999). Shifting discourses in language studies in South Africa. In Knowledge in Black and White: The Impact of Apartheid on the Production and Reproduction of Knowledge, Kwesi Kwaa Prah (ed.), 143-148. Cape Town: Centre for Advance Studies of African Society.

Mühlhäusler, Peter (1996). Linguistic Ecology: Language Change and Linguistic Imperialism in the Pacific Region. London: Routledge.

Nakata, Martin (1999). History, cultural diversity and English language teaching. In Double Power: English Literacy and Indigenous Education, P. Wignell (ed.), 5-22. Canberra: NLLIA.

-(2000). History, cultural diversity and English language teaching. In Multiliteracies: Literacy Learning and the Design of Social Futures, B. Cope and M. Kalantzis (eds.), 106-120. London: Routledge.

Pennycook, Alastair (1998). English and the Discourses of Colonialism. London: Routledge.

- (2000). Language, ideology and hindsight: lessons from colonial language policies. In Ideology, Politics, and Language Policies: Focus on English, Thomas Ricento (ed.), 49-65. Amsterdam: Benjamins.

-(2001). Critical Applied Linguistics: A Critical Introduction. Mahwah, NJ: Erlbaum.

- (2002). Language policy and docile bodies: Hong Kong and governmentality. In Language Policies in Education: Critical Issues, James Tollefson (ed.), 91-110. Mahwah, NJ: Erlbaum.

Rajagopalan, Kanavillil (1999). Of EFL teachers, conscience, and cowardice. ELT Journal 53(3), 200-206.

Report (1883). Report of the Education Commission Appointed by His Excellency Sir John Pope Hennessy, K.C.M.G. ... to Consider Certain Questions Connected with Education in Hong Kong, 1882. Hong Kong: Hong Kong Government.

Ricento, Thomas (2000). Ideology, politics and language policies: Introduction. In Ideology, Politics, and Language Policies: Focus on English, T. Ricento (ed.), 1-8. Amsterdam: Benjamins.

Romaine, Suzanne (1994). Language in Society: An Introduction to Sociolinguistics. Oxford: Oxford University Press. 


\section{A. Pennycook}

Rose, Nikolas (1996). Governing "advanced" liberal democracies. In Foucault and Political Reason: Liberalism, Neo-Liberalism and Rationalities of Government, A. Barry, T. Osborne, and N. Rose (eds.), 37-64. London: UCL Press.

Said, Edward (1993). Culture and Imperialism. New York: Vintage.

Singh, Jyotsna (1996). Colonial Narratives/Cultural Dialogues: "Discoveries" of India in the Language of Colonialism. London: Routledge.

Skutnabb-Kangas, Tove (2000). Linguistic Genocide in Education or Worldwide Diversity and Human Rights? Marwah, NJ: Erlbaum.

Smith, Peter (1987). Education and Colonial Control on Papua New Guinea; A Documentary History. Melbourne: Longman Cheshire.

Spivak, Gayatri (1993). Outside in the Teaching Machine. New York: Routledge.

Straits Settlements (various years). Straits Settlements Annual Departmental Reports. Singapore: Government Printing Office.

Sweeting, Anthony (1992). Hong Kong education within historical processes. In Education and Society in Hong Kong: Toward One Country and Two Systems, G.A. Postiglione (ed.). 39-81. Hong Kong: Hong Kong University Press.

Walton, Christine (1996). Critical Social Literacies. Darwin: Northern Territory University Press.

Young, Robert (1995). Colonial Desire: Hybridity in Theory, Culture and Race. London: Routledge. 